\title{
Evaluating Key Factors of Container Shipping Lines from the Perspective of High-tech Industry Shippers
}

\author{
Chien-Lung Hsu \\ Department of International Business Administration, Chinese Culture University, Taipei, Taiwan, ROC \\ Tien-Chun Ho \\ Department of Shipping and Transportation Management, National Penghu University of Science and Technology, \\ Penghu, Taiwan, ROC, htc0220@gms.npu.edu.tw
}

Follow this and additional works at: https://jmstt.ntou.edu.tw/journal

Part of the Fresh Water Studies Commons, Marine Biology Commons, Ocean Engineering Commons, Oceanography Commons, and the Other Oceanography and Atmospheric Sciences and Meteorology Commons

\section{Recommended Citation}

Hsu, Chien-Lung and Ho, Tien-Chun (2021) "Evaluating Key Factors of Container Shipping Lines from the Perspective of High-tech Industry Shippers," Journal of Marine Science and Technology. Vol. 29: Iss. 1, Article 3.

DOI: $10.51400 / 2709-6998.1002$

Available at: https://jmstt.ntou.edu.tw/journal/vol29/iss1/3

This Research Article is brought to you for free and open access by Journal of Marine Science and Technology. It has been accepted for inclusion in Journal of Marine Science and Technology by an authorized editor of Journal of Marine Science and Technology. 


\title{
Evaluating Key Factors of Container Shipping Lines from the Perspective of High-Tech Industry Shippers
}

\author{
Chien-Lung Hsu ${ }^{a}$, Tien-Chun Ho ${ }^{b, *}$ \\ ${ }^{a}$ Department of International Business Administration, Chinese Culture University, Taipei, Taiwan, ROC \\ ${ }^{\mathrm{b}}$ Department of Shipping and Transportation Management, National Penghu University of Science and Technology, Penghu, Taiwan, \\ ROC
}

\begin{abstract}
Because of the changes in customers' needs and demands created by the development of container transport in the 1960s, the global container transport business has become increasingly competitive. With the high-tech industry ranged with one of the few competitive industries in Taiwan from 2002, container shipping lines have been forced to implement innovative operating patterns to meet the evolving demands of the high-tech industry shippers. This study conducts a survey questionnaire of domestic high-tech industry shippers to explore the different factors affecting their selection of container shipping lines, evaluating the key influencing factors by maritime marketing's 4C framework: customer needs, customer costs, customer communication, and customer convenience. It aims to detect the appropriateness of key influencing factors and the correlation between them for high-tech industry shippers selecting container shipping lines by the Fuzzy Delphi Method and the Revised Decision-Making Trial and Evaluation Laboratory (the Revised DEMATEL). The conclusions indicates management implications and recommendations for container shipping lines to develop future operating strategies.
\end{abstract}

Keywords: Container shipping lines, Maritime marketing, the high-tech industry shippers, the Revised Decision-Making Trial and Evaluation Laboratory (the Revised DEMATEL)

\section{Introduction}

C ontainer transport has been deeply influenced by the needs of the international economy and trade since 1960s. In recent years, the container shipping market has become global, mature, and highly rival. Due to economic globalization and trading trends, it has grown increasingly competitive in the international business environment of container transport. Market uncertainty and unpredictable shipping changes have been the main factors affecting shippers' choices of container shipping lines (CSLs). When selecting a carrier, shippers consider freight tariffs most [1]. Besides the shipping costs, shippers weigh the service quality of shipping including schedule accuracy, cargo security, cargo tracking systems, and transhipment arrangements [2-4]. In addition, previous experiences with CSLs services could leave specific impressions on shippers. If CSLs get a better understanding of the frequent changes in shippers' needs, they can improve their operating performance in the uncertain shipping market through contingency plans such as reducing shipping costs, improving communication with customers, and providing more convenient services.

The "two-trillion and twin-star development program" in 2002 and the "national development plan" 
in 2008 laid the foundation for the vital position of semiconductors and video displays in Taiwan's future national industrial development. In nowadays, the high-tech industry (HTI) has become one of the few competitory industries in Taiwan. As the semiconductor manufacturing equipment is more time flexible to consumer electronics, sea transport is their main delivery mode, with air transport used only for urgent shipments. Considering the increasing global competitiveness of Taiwan's HTI and the enlarging volume of freight, HTI oriented CSLs should have a more in-depth understanding of the changes in the shipping market and of the demands of HTI in order to enhance customer satisfaction and loyalty. In reality, former researches on shippers' choices about CSLs were based on general shippers and lack of practical values for CSLs management. They have failed to precisely render the actual situation of the container shipping market owing to no analysis of the demands of HTI consignments. Therefore, this study aims to analyze the key factors influencing Taiwan's HTIs when selecting CSLs from the perspective of HTI shippers.

The research combines the Fuzzy Delphi Method (FDM) with the Revised Decision-Making Trial and Evaluation Laboratory (the Revised DEMATEL) analysis in order to apply more stringent subcriteria for the selection process. The FDM can effectively deal with ambiguity while retaining the semantic ambiguity of the data obtained from a group of experts. On the other hand, the Revised DEMATEL analysis offers an initial direct relational matrix for defining the suitability and relevance of key factors influencing a HTI's process of selecting CSLs, and clarifying the causality between the key influencing factors. With the two methods, the study not only defines the suitability and relevance of key and affecting factors, but adopt the $4 \mathrm{Cs}$ criteria of customer orientation to compare HTISs selections of CSLs. Following this instruction, section two reviews the related literature on the choice of shippers for CSLs and their proposed consolidation. Section three explores methods and the assessment framework. The fourth section provides an empirical analysis of HTISs choices for CSLs. At last, conclusions and recommendations are presented in section five.

\section{Literature review}

This section reviews the key factors influencing container transport, plus the related literature on research methods; then provides comprehensive discussions.

\subsection{Attributes of the maritime service of container shipping carriers}

Whether plying long- or short-distance sea transport routes, the needs of shippers vary over time. McGinnis [5] studied the key factors influencing a shipper's choice of CSLs, with the consideration of delivery speed, reliable schedules, freight tariffs, and cargo damage claims. It concluded that delivery speed and reliable schedules are the most important factors for shippers. In 1980s when freight charges did not vary greatly, carrier reputation was a determining factor in a shipper's decisions [6]. If CSLs creates a better reputation and brand equity, it would increase the differentiation advantages of the company [7].

Freight rates are another important factor for shippers when selecting CSLs [2,8]. However, the importance of freight rates may differ over time [9]. In the early 1990s, the most important factor changed from the carrier's reputation to transit time $[2,3]$. If CSLs do not match transit time with schedules, transport costs would increase [10]. Another research found that transport reliability and flexible communication are more important than freight tariffs [11]. Despite of the needs of shippers, freight tariffs, transit time, sailing frequency, and transport reliability are the primary motivations for shippers to change transport modes [12].

With the vigorous development of the logistics industry, CSLs have responded to shippers' logistic needs through expanding their service scope in a vertically integrated manner, combining transport processes, efficient container yards and ports, and adding branches or commissioned agents to develop their service scale $[13,14]$. Linking such changes with the concept of supply chain management, carriers need to apply an intermodal transport model from which to choose the lowest cost combination that meets a shipper's needs [15]. With these steps: integrating logistics operations, selecting ports adjacent to shippers, improving operational efficiency effectively, and reducing operating costs, CSLs could enhance their market competitiveness [16,17]. For instance, more concentrated sailing frequencies, higher transit time reliability, and quicker transfers assist them in reducing logistics costs [18]. However, to meet shippers' urgent needs, CSLs must regard not only transhipment 
arrangements but service fixed routes, ports, timing, and schedules [4].

CSLs with better logistics capabilities, flexible operations, and reduced costs are able to improve shippers' willingness to work together better $[19,20]$. In addition, timely delivery, lower freight rates, and integrated inland transport are the key factors for shippers in selecting CSLs [21]. The main factor behind shipping delays and increasing logistics costs is long waiting times in port [22]. Therefore, port operational efficiency and cost are factors that both carriers and shippers value [23]. When CSLs are faced with globalized competition, the following characteristics are their potential advantages: lower freight rates, excellent transport quality, and accurate delivery services [24]. On the other hand, ecommerce also provides customers with more value-added services [25]. If CSLs offer an online cargo tracking and query system and respond quickly to shippers' requests, they could effectively reduce damage rates during handling, improve security during transport, and have reliable and accurate schedules [26]. Moreover, the ability to eligibly reserve shipping space $[27,28]$ is also a key factor for shippers when selecting CSLs.

Since transport is a part of the service industry, CSLs must understand the various needs of shippers in order to effectively maintain existing relationships and develop new customers. In addition to factors such as transport reliability and safety, there are other key influencing factors for shippers when choosing CSLs: low costs, professional expertise, company reputation, transit time, service scope, integrated logistics, concentrated sailing frequency, implementation of e-commerce, accurate documentation [29], customs clearance efficiency [23], varied container types [30], good service attitude [31], and frequent visits to regulars [32].

\subsection{Related literature and research methods}

The fuzzy set theory (FST) by Zadeh copes with the imprecision and uncertainty which is inherent to human judgment in decision making processes through the use of linguistic terms and degrees of membership [33]. A fuzzy set is a class of objects with grades of membership. The grades present the degree of stability to which certain element belongs to a fuzzy set. CSLs assessment and selection are usually multi-criteria decision problems which, in actual shipping contexts, may be solved without precise information. Hence, the decision process of purchasing could be modeled and structured in a realistic way. In the field of transport, various authors have suggested a fuzzy set theory to inspect uncertainty and imprecision in choice situations. The theory could model vague preferences in a mathematically precise way, such as setting weights of performance scores on criteria. In addition, FST can be combined with other research methods to improve the quality of the final tools.

The Delphi Method is a systematic method to expedite expert group decisions. Through specific measurement steps of the Delphi Method in terms of reliability and validity, a research could avoid some error variability, and assure the level of reliability and validity [34]. Murray et al. [35] first applied fuzzy logic to the Delphi Method. In addition to reducing the number of surveys, it's also possible to solve the ambiguity of questionnaire questions and of expert opinions through semantic changes, thus giving a more consummate expression of their opinions. Ishikawa et al. [36] further extended the Fuzzy Delphi Method (FDM) with the concept of cumulative frequency distribution and fuzzy integration. It applied the fuzzy numbers to deal with the expertise captured by the Delphi Method. This method has the advantages of both conferences and traditional questionnaires due to the confidentiality of questionnaires and the effect of brainstorming. In conclusion, the FDM could deal with ambiguity and retain more expertise [37]. Compared to the traditional Delphi Method, it reaches a greater degree of consensus since taking semantic vagueness into account, and retains more complete information [38]. The specific procedures of the Delphi Method not only assist in avoiding errors, but ensure a certain degree of reliability and validity [34].

The FDM has been extensively applied to the selection of evaluation criteria in science and technology forecasting, public policy analysis, program planning, and other fields. For instance, it explored important evaluation criteria in the third-party logistics industry in order to provide an effective decision-making tool for enhancing customer service and reducing costs [39]. Another case was establishing supply chain risk assessment indicators [40]. Therefore, the related businesses can reduce supply chain risks, improve resilience, and develop appropriate business strategies to meet customers' needs in an increasingly competitive environment. Sheu et al. [41] explored the key factors and importance of clustering in Taiwan's intelligent transport system with the FDM and fuzzy hierarchical analysis to provide a reference for government to promote relevant industry clustering decisions. To summarize, the FDM is beneficial for offering more objective evaluation factors for group decisions. 
Subsequently, the DEMATEL was developed by the Battelle Memorial Institute of the Geneva Research Centre between 1972 and 1976. It solved sophisticated problems and improved the understanding of specific problems [42]. Through comparing the interrelationship between factors, the direct, indirect and combined effects among them can be calculated to clarify the nature of problems, thus contributing to research of countermeasures for relevant issues [43]. By Fuzzy DEMATEL, decision-makers could make decisions in an unstable environment [44]. For instance, airlines conducted an analysis of safety management systems [45]. Governments established an impact relation map and a network relation map to explore causal relationships that influence transport policy decisions [46]. Carriers explored key determining factors when choosing shippers on the basis of relevant environmental factors [47].

Through opinions based on practical experience provided by survey questionnaires, DEMATEL can be used to understand the causal relationships and level of influence of the factors that shippers consider selecting a carrier. Nevertheless, its initial direct relationship matrix may not show convergence. Fortunately, the Revised DEMATEL improves the previous problem [48]. [49] and [50] analyzed the correlation between the key influencing factors for CSLs in selecting ship management companies, and the ones for ocean freight forwarders in selecting CSLs by the Revised DEMATEL. Their purpose was to find the most influential and affected relevant factors, and to effectively understand the correlation between the key factors influencing CSLs and freight forwarders for these issues.

\subsection{Comprehensive discussions}

It's necessary for CSLs to understand the needs of shippers in order to provide the best shipping service and develop different marketing strategies. This study compiles the evaluation criteria for the factors influencing Taiwan's HTIs when choosing container shippers from the standpoint of HTIs. Through the FDM, it leverages relevant work experience and objective expertise, then eliminating the uncertainty and ambiguity of expert opinion in order to collect the appropriate assessment criteria effectively. The Revised DEMTEL, which could achieve the convergence effect of the initial direct relation matrix, benefits to explore the causality between the evaluation criteria. The results could serve as the basis for CSLs' development of ocean freight marketing strategies.

Considering the contributions from previous related studies, this study would bring together the factors influencing shippers when choosing CSLs and the elements that CSLs should possess, as shown in Table 1.

As shown in Table 1, before 2000, dedicated wharves and documentation accuracy were not considered significant by shippers; after 2000, the underrated factors were a company's financial status, and staff appearance. On the other hand, the following factors had all become important considerations for shippers when selecting CSLs: customes clearance efficiency, container types and condition, megaships, convenience of obtaining equipment, ecommerce systems, delivery service attitude, simple transport procedures, freight tariffs, timely delivery, transport reliability, sailing frequency, integrated logistics operations, transit time, maritime expertise, cargo security, portfolio of operating routes, maintenance of business relationship, corporate reputation and image, freight surcharges, direct access network, and cargo handling charges.

\section{Research methods and evaluation framework}

The following describes the research methods and framework for assessing the influencing factors, along with the key evaluation criteria, sub-criteria and their implications.

\subsection{Fuzzy Delphi Method}

In view of the fact that the traditional Delphi Method requires several times to meet acceptable expert standards of conformity, it is not easy to reach a convergence in the opinions of experts [56]. However, if fuzzy theory is applied to the Delphi Method, not only can similar results be obtained, but the time and expense of the survey can be reduced. Thus, Fuzzy Delphi Method is regarded as suitable for selecting the key evaluation criteria [57]. Subsequently, Wang et al. [58] pointed out that FDM can extract specific key factors from among various influencing factors. Therefore, the study adopts the Revised FDM based on triangular fuzzy numbers to conduct an appropriate analysis of the key factors influencing HTISs when selecting CSLs, which not only solves the shortcomings of the 
Table 1. Relevant sub-criterion of factors influencing maritime service for CSLs.

\begin{tabular}{|c|c|c|}
\hline Influencing Factors & Before 2000 & After 2000 \\
\hline Financial KPI report & McGinnis [1]; Brown [30] & \\
\hline Staff Appearance & $\begin{array}{l}\text { Subhash and Sanjay [27]; Brooks [6]; Chow } \\
\text { and Poist [31] }\end{array}$ & \\
\hline Dedicated wharves & & $\begin{array}{l}\text { Yang et al. [28]; Vernimmen et al. [10]; } \\
\text { Panayides [22]; Notteboom [18] }\end{array}$ \\
\hline Document accuracy & & Fanam et al. [51]; Yen and Chen [29] \\
\hline Customs clearance efficiency & Slack [23] & Chen [52] \\
\hline Container types and condition & Brown [30] & Yen and Chen [29] \\
\hline Megaships & Mentzer et al. [11]; McGinnis [1] & Yang et al. [28] \\
\hline Convenience of obtaining equipment & $\begin{array}{l}\text { Subhash and Sanjay [27]; McGinnis [1]; } \\
\text { Chow and Poist [31] }\end{array}$ & $\begin{array}{l}\text { Fanam and Ackerly [53]; Liang et al. [7]; } \\
\text { Yen and Chen [29] }\end{array}$ \\
\hline e-commerce systems & McGinnis [1]; Chow and Poist [31] & $\begin{array}{l}\text { Fanam [51]; Penaloza [25]; Yen and Chen } \\
\text { [29] }\end{array}$ \\
\hline Delivery service attitude & $\begin{array}{l}\text { Subhash and Sanjay [27]; Brooks [26]; } \\
\text { Chow and Poist [31] }\end{array}$ & Chen [52] \\
\hline Simple transport procedures & Chow and Poist [31] & $\begin{array}{l}\text { Yang et al. [28]; Liang et al. [7]; Yen and } \\
\text { Chen [29] }\end{array}$ \\
\hline Freight tariffs & $\begin{array}{l}\text { Mentzer et al. [11]; Subhash and Sanjay } \\
\text { [27]; Brown [30]; Murphy and Hall [9]; } \\
\text { McGinnis [1,5]; Brooks [2,6,26]; Chow and } \\
\text { Poist [31]; Krapfel and Mentzer [15] }\end{array}$ & $\begin{array}{l}\text { Fanam and Ackerly [53]; Fanam et al. [51]; } \\
\text { Rogerson et al. [19]; Ng et al. [8]; Chen [52]; } \\
\text { Brooks and Trifts [12]; Liang [7]; Salleh [24]; } \\
\text { Zsidisin et al. [21]; Douglas et al. [13]; } \\
\text { Wilding and Juriado [20] }\end{array}$ \\
\hline Timely delivery & $\begin{array}{l}\text { Subhash and Sanjay [27]; Brooks [3]; } \\
\text { McGinnis [1]; Chow and Poist [31] }\end{array}$ & $\begin{array}{l}\text { Chen [52]; Brooks and Trifts [12]; Liang } \\
\text { et al. [7]; Vernimmen et al. [10]; Salleh [24]; } \\
\text { Penaloza et al. [25]; Zsidisin et al. [21]; } \\
\text { Douglas et al. [13]; Notteboom [18]; Liao } \\
\text { et al. [4] }\end{array}$ \\
\hline Transport reliability & $\begin{array}{l}\text { Mentzer et al. [11]; Subhash and Sanjay } \\
\text { [27]; McGinnis [1,5]; Brooks [6]; Chow and } \\
\text { Poist [31] }\end{array}$ & $\begin{array}{l}\text { Fanam and Ackerly [53]; Fanam et al. [51]; } \\
\text { Chen [52]; Brooks and Trifts [12]; } \\
\text { Vernimmen et al. [10]; Salleh [24]; } \\
\text { Panayides [22]; Notteboom [18]; Yen and } \\
\text { Chen [29]; Liao et al. [4]; Premeaux [54] }\end{array}$ \\
\hline Sailing frequency & Brown [30]; Slack [23]; Brooks [2,6] & $\begin{array}{l}\text { Fanam and Ackerly [53]; Fanam et al. [51]; } \\
\text { Yang et al. [28]; Brooks and Trifts [12]; } \\
\text { Vernimmen et al. [10]; Notteboom [18] }\end{array}$ \\
\hline Integrated logistics operations & $\begin{array}{l}\text { Brown [30]; Brooks [6]; Krapfel and } \\
\text { Mentzer [15] }\end{array}$ & $\begin{array}{l}\text { Fanam and Ackerly [53]; Fanam et al. [51]; } \\
\text { Rogerson et al. [19]; Yang et al. [28]; } \\
\text { Vernimmen et al. [10]; Zsidisin et al. [21]; } \\
\text { Panayides [22]; Yeung [14]; Yen and Chen } \\
\text { [29]; Wilding and Juriado [20]; Tiwari et al. } \\
\text { [17] }\end{array}$ \\
\hline Transit time & $\begin{array}{l}\text { Subhash and Sanjay [27]; Brown [30]; } \\
\text { McGinnis [1,5]; Slack [23]; Brooks [2,6] }\end{array}$ & $\begin{array}{l}\text { Fanam and Ackerly [53]; Finnsgård et al. } \\
\text { [55]; Yang et al. [28]; Chen [52]; Brooks and } \\
\text { Trifts [12]; Zsidisin et al. [21]; Douglas et al. } \\
\text { [13] }\end{array}$ \\
\hline Maritime expertise & $\begin{array}{l}\text { Subhash and Sanjay [27]; Brooks [6,26]; } \\
\text { McGinnis [1,5]; Chow and Poist [31] }\end{array}$ & $\begin{array}{l}\text { Fanam and Ackerly [53]; Liang et al. [7]; } \\
\text { Yen and Chen [29] }\end{array}$ \\
\hline Cargo security & $\begin{array}{l}\text { Subhash and Sanjay [27]; Slack [23]; Brooks } \\
\text { [6]; Chow and Poist [31] }\end{array}$ & $\begin{array}{l}\text { Fanam and Ackerly [53]; Chen [52]; Liang } \\
\text { et al. [7]; Yen and Chen [29] }\end{array}$ \\
\hline Portfolio of operating routes & Brown [30]; Brooks [6] & $\begin{array}{l}\text { Fanam and Ackerly [53]; Rogerson et al. } \\
\text { [19]; Vernimmen et al. [10]; Douglas et al. } \\
\text { [13]; Liao et al. [4] }\end{array}$ \\
\hline Maintenance of business relationship & $\begin{array}{l}\text { Panayides and Gray [32]; Subhash and } \\
\text { Sanjay [27]; Brown [30] }\end{array}$ & $\begin{array}{l}\text { Yang et al. [28]; Yen and Chen [29]; Tiwari } \\
\text { et al. [17] }\end{array}$ \\
\hline Corporate reputation and image & Brooks [3]; Slack [23]; Chow and Poist [31] & $\begin{array}{l}\text { Fanam and Ackerly [53]; Chen [52]; Yen } \\
\text { and Chen [29] }\end{array}$ \\
\hline Freight surcharges & Slack [23] & $\begin{array}{l}\text { Rogerson et al. [19]; Yang [28]; Ng et al. [8]; } \\
\text { Wilding and Juriado [20]; Zsidisin [21] }\end{array}$ \\
\hline Direct access network & Subhash and Sanjay [27] & Yen and Chen [29] \\
\hline Cargo handling charges & Slack [23] & Chou [16]; $\mathrm{Ng}$ et al. [8] \\
\hline
\end{tabular}


conventional Delphi Method, but ensure that the results are not easily affected by extreme opinions. The operational process is as follows:

\subsubsection{Aggregate experts' opinions}

The questionnaires involves semantic variables to find each expert's evaluation index of the importance of each factor.

\subsubsection{Establish a symmetric triangular fuzzy number}

It calculates the triangular fuzzy number evaluation weight from the group of experts. The formula is shown in Eq. (1). Assuming the appraisal index of influencing factor $k(k=1,2,3, \ldots, m)$ for expert $i$ $(i=1,2,3, \ldots, n)$ is $w i k=(L i k, M i k, U i k)$, then the fuzzy weight $w k$ of the influence factor $k$ is:

$$
\tilde{W} k=(L k, M k, U k), k=1,2,3, \ldots, n
$$

Where $L k=\min _{i}\{L i k\}, \quad M k=\frac{1}{n} \sum_{i=1}^{n} M i k, \quad U k=$ $\max \{U i k\}$

\subsubsection{Defuzzification}

In general, the Graded Multiple Integrals Representation (GMIR) Method [59] can convert fuzzy sets into explicit sets to facilitate decision-making. The GMIR defuzzifies the fuzzy weights $\tilde{W} k$ into explicit weights $\tilde{S} k$, as shown in Eq. (2) below.

$$
\begin{aligned}
S k=\frac{L k+4 \cdot M k+U k}{6} \quad i & =1,2,3, \ldots, m, \quad k \\
& =1,2,3, \ldots, n
\end{aligned}
$$

This study defuzzifies the weight of each influencing factor into a non-fuzzy value by GMIR in order to obtain each influencing factor's weight. Next, it considers the thresholds adopted in previous studies of transport-related fields to determine the threshold for this article. Any value greater than this threshold are accepted and those below the threshold are removed, thereby screening the evaluation criteria.

\subsection{The revised DEMATEL analysis}

The DEMATEL analysis was developed by the Battelle Memorial Institute of the Geneva Research Centre between 1972 and 1976. It is a method of combining linear algebra with expert questionnaires to clarify the causality of complex issues. By observing the degree of interaction between factors and using a matrix and related mathematical theory to calculate the causal relationship and degree of impact of all factors, this method can effectively clarify complex causal structures and the directionality of the influencing factors $[60,61]$. Since the initial direct relationship matrix may not produce a convergence effect

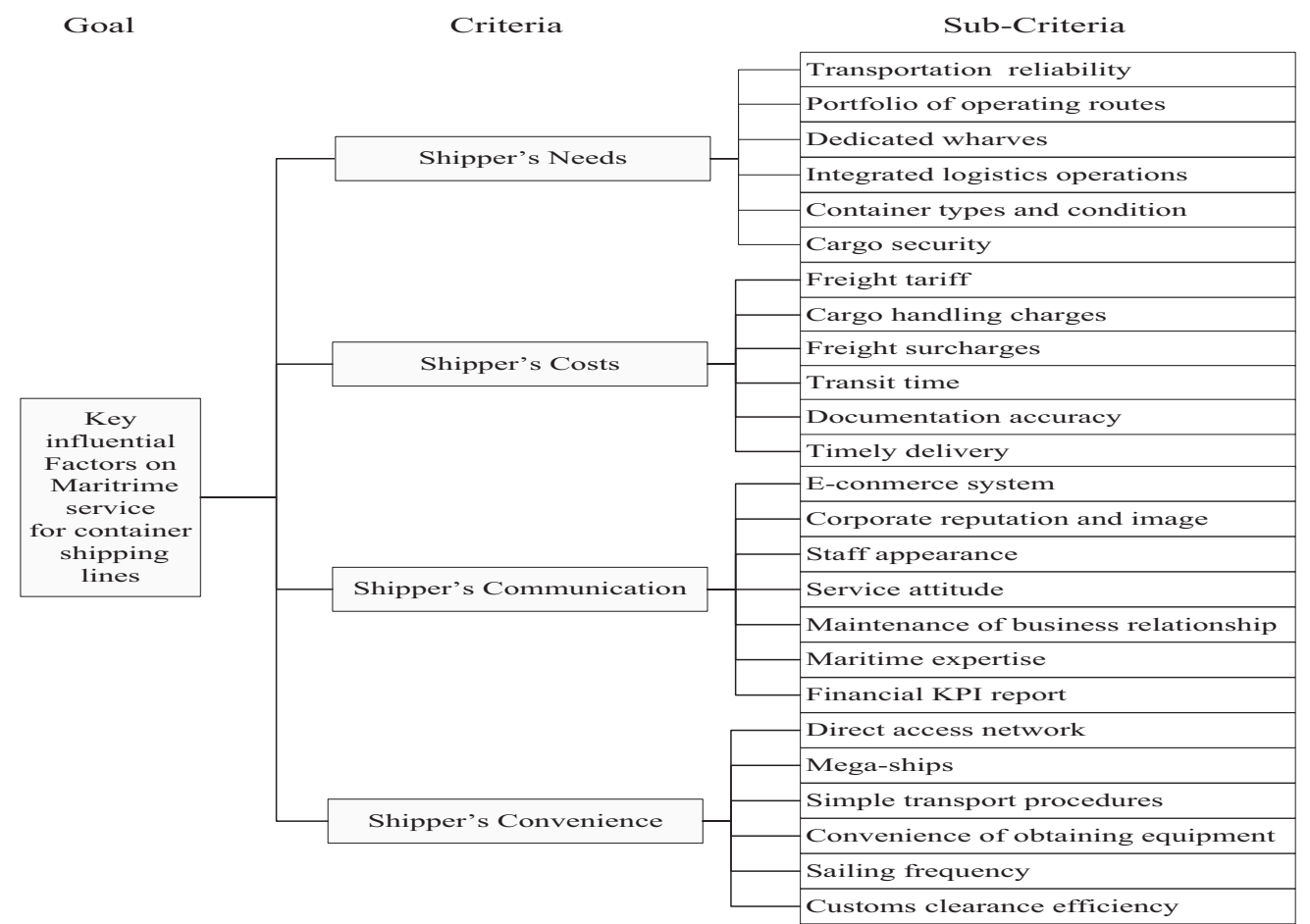

Fig. 1. Evaluation framework of key influencing factors for HTISs selecting CSLs. 
Table 2. The assurance analysis of factors influencing HTISs' selection of CSLs.

\begin{tabular}{|c|c|c|c|}
\hline Criteria & Sub-criteria & Geometric mean & Threshold $\geq 0.7$ \\
\hline \multirow[t]{6}{*}{ Shipper's needs } & Transport reliability & 0.789 & \\
\hline & Portfolio of operating routes & 0.672 & Ignore \\
\hline & Dedicated wharves & 0.574 & Ignore \\
\hline & Integrated logistics operations & 0.654 & Ignore \\
\hline & Container types and condition & 0.651 & Ignore \\
\hline & Cargo transport security & 0.731 & \\
\hline \multirow[t]{6}{*}{ Shipper's costs } & Freight tariffs & 0.733 & \\
\hline & Cargo handling charges & 0.695 & Ignore \\
\hline & Freight surcharges & 0.692 & Ignore \\
\hline & Transit time & 0.752 & \\
\hline & Documentation costs & 0.743 & \\
\hline & Timely delivery & 0.762 & \\
\hline \multirow[t]{7}{*}{ Shipper's communication } & E-commerce systems & 0.649 & Ignore \\
\hline & Corporate reputation and image & 0.552 & Ignore \\
\hline & Staff personal appearance & 0.509 & Ignore \\
\hline & Maintenance of Business Relationship & 0.717 & \\
\hline & Transport service attitude & 0.637 & Ignore \\
\hline & Maritime expertise & 0.705 & \\
\hline & Financial KPI report & 0.536 & Ignore \\
\hline \multirow[t]{6}{*}{ Shipper's convenience } & Direct access network & 0.659 & Ignore \\
\hline & Mega-ships & 0.527 & Ignore \\
\hline & Convenient shipping procedures & 0.725 & \\
\hline & Equipment accessibility & 0.662 & Ignore \\
\hline & Sailing frequency & 0.690 & Ignore \\
\hline & Customs clearance efficiency & 0.711 & \\
\hline
\end{tabular}

when using the original version of DEMATEL, the Revised DEMATEL improves on this disadvantage and produces more accurate results [48]. The formula for calculating it is shown as follows:

\subsubsection{Define and determine the relationship between the factors}

Filter and define factors in the system are based on experts' experience and the literature review.

\subsubsection{Calculate the initial average matrix}

Let $A=($ aij $) n \times n$ be an average matrix of the respondents' direct matrices in which the entry $(i, j)$ indicates the direct influence factor $i$ exerts on factor $j$. The initial average matrix $A=(a i j) n \times n$ is shown in formula (3) below:

$A=\frac{1}{H} \sum_{k=1}^{H} B^{(k)}$
Where $B^{k}$ is the matrix of the respondent $k$ 's answer.

\subsubsection{Calculate the initial-direct relation matrix} normalized to $X$

Calculate the initial-direct relation matrix normalized to $X$ with formula (4) as follows:

$X=\frac{A}{S}$

Where $s$ is calculated using formula (5) as follows:

$s=\max \left(\max _{1 \leq i \leq n} \sum_{j=1}^{n} a i j, \epsilon+\max _{1 \leq j \leq n} \sum_{i=1}^{n} a i j\right)$

In this formula, $\epsilon$ is a very small positive number.

\subsubsection{Derive the total influence matrix $S$}

All the matrices with indirect influence are $X 2, X 3$, $\ldots, X k, \ldots, X^{\infty}$, and the total influence matrix is $S=X+$

Table 3. Correlation values of influencing factors.

\begin{tabular}{lllll}
\hline Factors which influence or are influenced & $D_{k}$ & $R_{k}$ & $D_{k+} R_{k}($ ranking) & $D_{k+} R_{k}($ ranking) \\
\hline (C11) Transport reliability & 0.5386 & 0.5274 & $1.0660(1)$ & $0.0112(4)$ \\
(C16) Cargo security & 0.3488 & 0.1750 & $0.5238(5)$ & $0.1738(3)$ \\
(C21) Freight tariffs & 0.5114 & 0.1649 & $0.6763(4)$ & $0.3465(1)$ \\
(C24) Transit time & 0.5259 & 0.3434 & $0.8693(2)$ & $0.1825(2)$ \\
(C26) Timely delivery & 0 & 0.7141 & $0.7141(3)$ & $-0.7141(5)$ \\
\hline
\end{tabular}




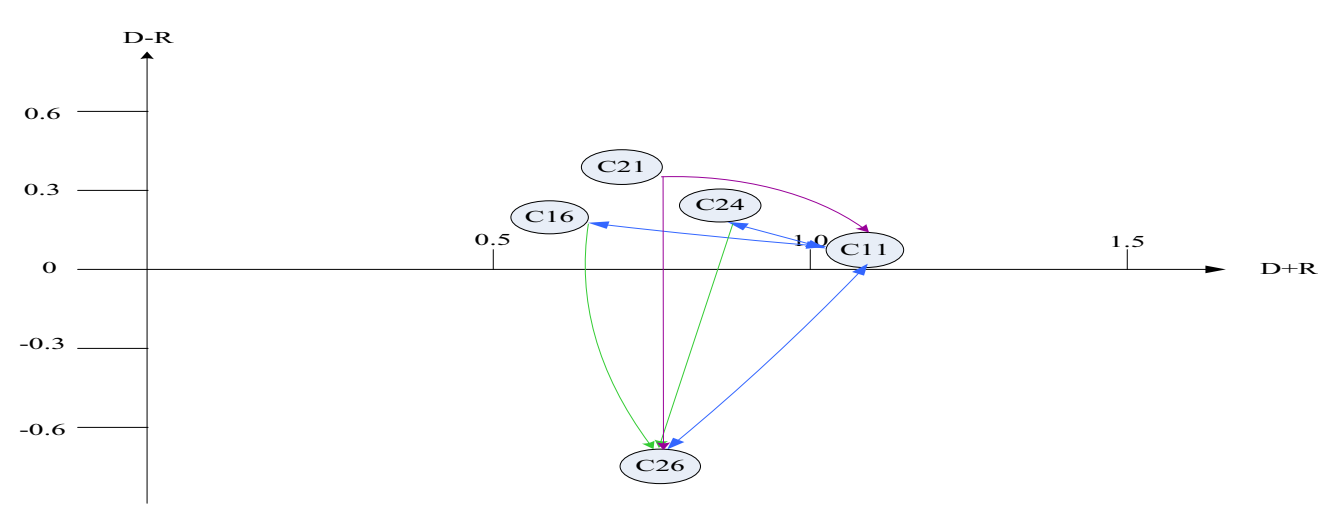

Fig. 2. Causal relationships of factors which influence or are influenced.

$X^{2}+, \ldots, X^{\infty}=\sum_{k=1}^{\infty} X^{k}$, which is equivalent to formula (6) as shown below:

$S=X(I-X)^{-1}$

\subsection{Evaluation framework of influencing factors}

The paper reviews the key factors influencing consolidating shippers' selection of CSLs on the basis of the literature review and the combined marketing 4Cs framework [62], including customer/ shipper needs, costs, communication, and convenience. Moreover, it evaluates the objectives, criteria, and sub-criteria to construct an evaluation framework of the key factors influencing HTISs when choosing CSLs, as shown in Fig. 1.

According to the literature review, the key influencing factors for shippers to select CSLs are based on the shipping marketing concepts distinguishing between the 4 aspects: shipper's needs, cost, communication, and convenience. Then, HTIS determines the most suitable key influencing factors by FDM, and assesses the correlation between the key influencing factors by Revised DEMATEL.

\section{Empirical analysis and discussion}

This section is based on the experience and knowledge of appropriate shipping industry experts obtained through an effective questionnaire. The study analyzes the appropriateness and relevance of the key factors influencing shippers' CSL choices, and considers the implications for CSL management.

\subsection{Survey Results}

The questionnaire conducts its survey through convenient sampling and email delivery, referring to Taiwan's Ministry of Economic Affairs' 2016 Directory of Excellent Exporters and Importers (2017) [63]. The study collects the data from an expert questionnaire. 40 experts are selected from industrial and academic institutions with professional knowledge and experience, with an average of working with the HTI over 10 years. It targets 25 high-level senior managers of HTI exporters and importers, including 19 in integrated circuit manufacture, 10 in photoelectric and optical related industry, 6 in computer and consumer electronics manufacturing industry, and 5 in electronics-related industry. Particularly, they are the managers responsible for selecting CSLs for their firms. A total of 40 questionnaires concerning the factors affecting HTI companies' selection of CSLs are issued, with 31 are responded and valid. The effective questionnaire response rate is $77.5 \%$.

\subsection{Appropriateness analysis of influencing factors}

The first stage explores the opinions of HTI experts and screen for the most critical evaluation subcriteria by the FDM and a threshold concept. An appropriateness level greater than $70 \%$ or $80 \%$ indicates that a criterion can be considered to be appropriate [64]. Most of the transport-related studies have set the threshold value at 0.7 [41,65]. In addition to satisfying the standard criteria for experts' consensus set by Hwang et al. [64]; the integrity of the criteria can also be ensured. This paper sets the geometric mean of the evaluation criteria greater than or equal to 0.7 as the appropriateness standard. Therefore, the evaluation subcriteria are retained. The screening results for selecting the evaluation criteria of the key factors influencing HTISs' selection of CSLs are shown in Table 2 .

In terms of evaluation sub-criteria, the research divides into $\mathbf{1 0}$ factors as the basis for a correlation 
analysis of key factors influencing HTISs' selection of CSLs: transport reliability, cargo security, freight tariffs, transit time, documentation costs, timely delivery, business relationship maintenance, maritime expertise, convenient shipping procedures, and customs clearance efficiency.

\subsection{Correlation analysis of influencing factors}

In order to obtain stronger correlation among key influencing factors, this study sets 0.16 as the threshold value. It removes any factors that have low correlation since a direct or indirect relationship value greater than 0.16 indicates greater significance. After obtaining the sum of the determinant for each row and column, the influencing factors and the total extent of their influence are calculated, and the key influencing factors are sorted according to the rank. $D i$ displays the total extent of the factor's influence on other factors, $R j$ shows the total extent to which the factor is influenced, and $(D k+R k) \mathrm{im}-$ plies the intensity of the relationship between the factor and other factors. The larger the value, the greater the total impact of the factor. $(D k-R k)$ indicates the extent of the factors' influence or by which it is influenced. A positive number signifies that the factor is an influencing factor, while a negative number means the factor is influenced by other factors. The numerical value indicates the causal relationship between key influencing factors given a set threshold value. The diagram of their causal relationships is shown in Table 3 and in Fig. 2.

Table 3 shows that, beyond a given threshold value, factors with a high degree of correlation contains transport reliability (C11), cargo security (C16), freight tariffs (C21), transit time (C24), and timely delivery (C25).

\subsection{Implications and discussions}

In terms of the main influencing factors, cargo transport costs, transit time, cargo security, and transport reliability are the primary affecting factors. First, cargo transport costs unilaterally influence transport reliability. Transport reliability bilaterally affects both transit time and transport security. In addition, HTISs are more sensitive to freight tariffs due to the global economic recession and slowdown in shipping growth. The cargo consignments of HTISs have high unit costs and are characterized by precision, timing, and a short shelf life. Besides transport costs, the main influencing factors include cargo security, transport reliability, and transit time.

The study discovers that timely delivery, a stable shipping schedule, cargo transport security, and transit time all affect the confidence level of HTISs in CSLs. Due to the rise of logistics and transport services, sea transport is just another logistics link. If a CSL effectively integrate logistics operations, they can not only reduce transit time and enhance timely delivery, cargo transport security, and flexible tariffs, but use their IT platforms to integrate freight forwarding, logistics operations, customs brokerage, warehousing, and distribution. Through increasing value-added services, they can improve profitability and raise the willingness of HTISs to use their services. Logistics operations assist CSLs in creating competitive advantages, and are significant in both enhancing corporate profitability and improving customer satisfaction [66]. In addition to providing their products and services, CSLs need to have sound logistics systems for the purpose of gaining market advantage [14].

The factor affected most by others among the major influencing factors is timely delivery. It can be unilaterally influenced by freight tariffs, transit time, and cargo transport security. When considering timely delivery, HTISs shall exercise discretion in giving thought to CSL's freight tariffs, cargo transport security, and transit time. On the other hand, in order to improve cargo transport security, shorten transit time, and reduce freight costs, CSLs shall integrate their logistics operations to lower operating costs through the consolidation of the transport processes. Then, they can provide more competitive freight rates and shorten the transit time, which increases the willingness of HTISs to use their services.

In addition, timely delivery and transport reliability have a mutual influence. Because maritime transport is more time-consuming than other modes of transport, CSLs must conform to legal requirements and transport safety regulations to maintain the safety of the carriers, stable schedules, and arrival times consistent with planned arrival times. Timely delivery would increase the acceptance for HTISs. Although freight tariffs is the key influencing factor, the transport reliability shows a higher overall impact. In other words, CSLs should not only be reliable carriers or focus on reducing 
freight costs. If they employ what above-mentioned and other key influencing factors to improve their timely delivery, they may be favoured by HTISs.

In the previous relevant literatures for shipper to select CSLs, the "shippers" refers to general shippers. Only rare of them separated OFFs from shippers. There was no other related literature. Therefore, this research summarizes the literatures on the factors affecting the selection of CSLs by all shippers from 1982 to 2019. The purpose is to assist HTIS in evaluating the factors by the FDM when selecting CSLs. Based on the results, transport reliability, cargo transport security, freight tariffs, transit time, documentation costs, timely delivery, business relationship maintenance, maritime expertise, convenient shipping procedures and customs clearance efficiency and other factors are more appropriate. It indicates that these criteria are more suitable for assessing the elements of HTIS choosing CSLs. The research is proved to be favorable for the CSLS' future reference toward market segmentation.

\section{Concluding remarks}

1. As global container transport is a mature global transport service business, it is deeply influenced by the global economy and the demands of trade. Market uncertainty and unpredictable changing factors in the shipping environment become the important references to HTISs' choices of CSLs. This study constructs an evaluation framework for assessing key factors influencing choices of CSLs from the standpoint of HTISs. The research design is based on four evaluation aspects, "shippers' demands, costs, communication and convenience," and 25 evaluation sub-criteria through a survey questionnaire targeting domestic HTISs. It first evaluates the relevance of evaluation sub-criteria by FDM; then examines the correlation between evaluation aspects and sub-criteria, lastly explores the relevance of the key factors influencing HTISs when selecting CSLs by the Revised DEMATEL.

2. As for the key influencing factors affecting HTISs when selecting CSLs, there are ten evaluation criteria: transport reliability, cargo security, freight tariffs, transit time, documentation accuracy, timely delivery, maintenance of business relationship, maritime expertise, simple transport procedures, and customs clearance efficiency. These factors are the most appropriate evaluation sub-criteria, and are used to process the correlation analysis of key factors. By the Revised DEMATELs, the main influencing factors are freight tariffs, transit time, and cargo security and transport reliability. Another main factor influenced by others is timely delivery.

3. For the selection of CSLs by OFFs, service quality, document accuracy, freight rates, schedule reliability and quick handling are the most influential factors to freight forwarders when purchasing liner shipping service [51]. In the research of fresh produce shippers, even though freight rates are high in Tasmania, Tasmania shippers do not highly concentrate on pricing [53]. The most critical influencing factors are cargo safety, following by network and schedule, corporate social responsibility, pricing of service and door-to-door service. The results suggests that HTIS should not place too much emphasis on freight tariffs when selecting CSLs, since one factor link with another ones. Freight tariffs will affect timely delivery and transport reliability. Transport reliability will interact with cargo security, transit time and timely delivery. In conclusion, timely delivery, transport reliability, cargo security and transit time are the key evaluation factors when selecting CSLs.

\section{References}

[1] McGinnis MA. The relative importance of cost and service in freight transportation choice: before and after deregulation. Transport J 1990;30(1):12-9.

[2] Brooks MR. Ocean carrier selection criteria in a new environment. Logist Transport Rev 1990;26(4):339-55.

[3] Brooks MR. Assessment of the ocean carrier decision environment: a longitudinal study. J Transport Res Forum 1991; 31(2):219-29.

[4] Liao YH, Lu HA, Tsao SM, Liao KH. Ship scheduling for container liner. J Chin Inst Transp 2004;16(3):203-26.

[5] McGinnis MA. Shipper attitudes toward freight transportation choice: a factor analytic study. Int J Phys Distrib Mater Manag 1979;10(1):25-34.

[6] Brooks MR. An alternative theoretical approach to the evaluation of liner shipping, part II: choice criteria. Marit Pol Manag 1985;12(2):145-55.

[7] Liang GS, Ding JF, Liu IW. Using conjoint analysis on the evaluation of brand equity for liner service companies: an empirical study of four international carriers. J Chin Inst Transp 2007;19(4):333-62.

[8] Ng ASF, Sun D, Jyotirmoyee B. Port choice of shipping lines and shippers in Australia. Asian Geogr 2013;30(2):143-68.

[9] Murphy PR, Hall PK. The relative importance of cost and service in freight transportation choice before and after deregulation: an update. Transport J 1995;35(1):30-9.

[10] Vernimmen B, Dullaert W, Engelen S. Schedule unreliability in liner shipping: origins and consequences for the hinterland supply chain. Marit Econ Logist 2007;9(3):193-213.

[11] Mentzer JT, Flint DJ, Kent JL. Developing a logistics service quality scale. J Bus Logist 1999;20(1):9-32. 
[12] Brooks MR, Trifts V. Short sea shipping in north America: understanding the requirements of atlantic Canadian shippers. Marit Pol Manag 2008;35(2):145-58.

[13] Douglas VM, Page TJ, Keller SB, Ozments J. Determining important carrier attributes: a fresh perspective using the theory of reasoned action. Transport J 2006;45(4):7-19.

[14] Yeung CL. The impact of third-party logistics performance on the logistics and export performance of users: an empirical study. Marit Econ Logist 2006;8(2):121-39.

[15] Krapfel RE, Mentzer JT. Shippers transportation choice processes under deregulation. Ind Market Manag 1982;11(3): 117-24.

[16] Chou CC. A Container throughput split model for international ports in Taiwan area. Transp Plan J 2005;34(4):501-23.

[17] Tiwari P, Itoh H, Doi M. Shippers' port and carrier selection behavior in China: a discrete choice analysis. Marit Econ Logist 2003;5(1):23-39.

[18] Notteboom TE. The time factor in liner shipping services. Marit Econ Logist 2006;8(1):19-39.

[19] Rogerson S, Andersson D, Johansson MI. Influence of context on the purchasing process for freight transport services. Int J Logist 2014;17(3):232-48.

[20] Wilding R, Juriado R. Customer perceptions on logistics outsourcing in the European consumer goods industry. Int J Phys Distrib Logist Manag 2004;34(8):628-44.

[21] Zsidisin GA, Voss MD, Schlosser M. Shipper-carrier relationships and their effect on carrier performance. Transport J 2007;46(2):5-18.

[22] Panayides PM. Maritime logistics and global supply chains: towards a research agenda. Marit Econ Logist 2006;8(1):3-18.

[23] Slack B. Containerization, Inter-port competition and port selection. Marit Pol Manag 1985;12(4):293-303.

[24] Salleh AL. Worldwide sourcing practice of Malaysian electrical and electronics companies. Busines Rev Cambridge 2007;8(2):61-7.

[25] Penaloza E, Brooks M, Marche S. Case study analysis of the impacts of electronic commerce on the strategic management of container shipping companies. Marit Pol Manag 2007;34(1):37-45.

[26] Brooks MR. Understanding the ocean container market - a seven country study. Marit Pol Manag 1995;22(1):39-49.

[27] Subhash CM, Sanjay SM. Important dimensions in ocean freight service: shippers' perspective. J Cust Serv Mark Manag 1997;3(3):85-100.

[28] Yang CC, Tai HH, Chiu WH. Factors influencing container carriers; use of coastal shipping. Marit Pol Manag 2014;41(2): 192-208.

[29] Yen JR, Chen SM. Modeling the shippers' behavior in shortsea routes. Maritime Q 2004;13(2):73-96.

[30] Brown DG. Internal dynamics of inventory - theoretic models for microeconomic transportation applications. Logist Transport Rev 1995;31(3):253-79.

[31] Chow G, Poist RF. The measurement of quality of service and the transportation purchase decision. Logist Transport Rev 1984;20(1):25-43.

[32] Panayides PM, Gray R. An empirical assessment of relational competitive advantage in professional ship management. Marit Pol Manag 1999;26(2):111-25.

[33] Simić D, Kovačević I, Svirčević V, Simić S. 50 years of fuzzy set theory and models for supplier assessment and selection: a literature review. J Appl Logic Part A 2017;24:85-96.

[34] Chen SH, Lin YJ. The key success factors of cross-functional team of new product development - a case study of a hightech company. Manag Inform Comput 2013;2(1):105-27.

[35] Murray TJ, Pipino LL, van Gigch JP. A pilot study of fuzzy set modification of Delphi. Hum Syst Manag 1985;5(1):76-80.

[36] Ishikawa A, Amagasa M, Shiga T, Tomizawa G, Tatsuta R, Mieno H. The max-min Delphi method and fuzzy Delphi method via fuzzy integration. Fuzzy Set Syst 1993;55(3):241-53.

[37] Liang LW, Li TH, Huang BY. Investigation of merging and acquisition of Taiwanese banks - application of the fuzzy Delphi method. Taiwan Banking Fin Q 2010;11(4):31-65.
[38] Yeh CC, Weng SL, Wu JH. A study comparing the Delphi method and fuzzy Delphi method. Surv Res - Method Appl 2007;21:31-58.

[39] Liu HT, Wang WK. An integrated fuzzy approach for provider evaluation and selection in third-party logistics. Expert Syst Appl 2009;36(3):4387-98.

[40] Wang XJ. An integrated fuzzy approach for the evaluation of supply chain risk mitigation strategies. Open J Soc Sci 2014; 2(9):161-6.

[41] Sheu JB, Lin SR, Hsin SC. The study on critical factors for industrial cluster of intelligent transportation systems industry in Taiwan. J Chin Inst Transp 2012;24(1):25-52.

[42] Tzeng GH, Chiang $\mathrm{CH}$, $\mathrm{Li} \mathrm{CW}$. Evaluating intertwined effects in e-learning programs: a novel hybrid MCDM model based on factor analysis and DEMATEL. Expert Syst Appl 2007;32(4):1028-44.

[43] Liu CZ, Lin CL. A study on leisure agricultural development of Tai-an village in Houli township - an application of the DEMATEL method. J Agric For 2005;54(4):263-82.

[44] Lin CJ, Wu WW. A causal analytical method for group decision-making under fuzzy environment. Expert Syst Appl 2008;34(1):205-13.

[45] Liou JH, Yen L, Tzeng GH. Building an effective safety management system for airlines. J Air Transport Manag 2008;14(1):20-6.

[46] Kuo SY, Chen SC. Transportation policy making using MCDM model: the case of hualien. Transp Plan J 2015;44(1): 25-44.

[47] Peng J, Kannan G, Devika K. Identification and evaluation of influential criteria for the selection of an environmental shipping carrier using DEMATEL: a case from India. Int J Shipp Transp Logist (IJSTL) 2015;7(6):719-41.

[48] Lee HS, Tzeng GH, Yeih WC, Wang YJ. Revised DEMATEL: resolving the infeasibility of DEMATEL. Appl Math Model 2013;37(10-11):6746-57.

[49] Ho TC, Chiu RH, Chung CC, Lee HS. Key influence factors for ocean freight forwarders selecting container shipping lines using the revised DEMATEL approach. J Mar Sci Technol 2017;25(3):299-310.

[50] Ho TC, Chung CC, Lee HS, Wang SC. An evaluation of the key influential factors for container shipping lines selecting ship management companies in Taiwan. Transp Plan J 2016; 45(3):217-34.

[51] Fanam PD, Nguyen HO, Cahoon S. Selection of ocean container carriers: one country's perspective. Afr J Bus Manag 2017;10(23):576-84.

[52] Chen HY. Analyzing the influential factors of heterogeneous selection behaviors of shippers. Master's thesis. 2009. Dept. of Shipping and Transportation Management, National Taiwan Ocean University, Keelung, Taiwan.

[53] Fanam PD, Ackerly L. Evaluating ocean carrier selection criteria: perspectives of tasmanian shippers. J Ship Trade 2019;4(1):1-16.

[54] Premeaux SR. Motor carrier selection criteria: perceptual differences between shippers and motor carriers. Transport J 2002;41(2):28-38.

[55] Finnsgård C, Kalantari J, Raza Z, Roso V, Woxenius J. Swedish shippers' strategies for coping with slow-steaming in deep sea container shipping. J Ship Trade 2018;3(1):1-24.

[56] $\mathrm{Wu} \mathrm{CH}$. Combining the fuzzy analytic hierarchy process and the fuzzy Delphi method for developing critical competences of electronic commerce professional managers. J Qual Q 2011;45(4):751-68.

[57] Lee AHI, Lin CY, Wang SR, Tu YM. The construction of a comprehensive model for production strategy evaluation. Fuzzy Optim Decis Making 2010;9(2):187-217.

[58] Wang WM, Lee AHI, Chang DT. An integrated FDM-ANP evaluation model for sustainable development of housing community. Optim Lett 2010;4:239-57.

[59] Chen $\mathrm{SH}$, Hsieh $\mathrm{CH}$. Representation, ranking, distance, and similarity of L-R type fuzzy number and application. Australian Journal of Intelligent Processing System 2000;6(4): 217-29. 
[60] Hsu CW, Kuo TC, Chen SH, Hu AH. Using DEMATEL to develop a carbon management model of supplier selection in green supply chain management. J Clean Prod 2013;56(1): $164-72$.

[61] Seyed-Hosseini SM, Safaei N, Asgharpour MJ. Reprioritization of failures in a system failure mode and effects analysis by decision making trial and evaluation laboratory technique. Reliab Eng Syst Saf 2006;91(8):872-81.

[62] Lauterborn R. New marketing: 4P's passé; C-words take over. In: Advertising Age, October 1; 1990. p. 26.
[63] Directory of excellent exporters/importers 2016, Ministry of Economic Affairs web. https://fbfh.trade.gov.tw/eai105/ index.asp. [Accessed 10 October 2017].

[64] Hwang KP, Lin CK, Hsu CH. A joint fuzzy AHP approach in prioritizing urban off-street parking sites. J Chin Inst Transp 2005;17(3):281-304.

[65] Chao CC, Yu PC. Quantitative evaluation model of air cargo competitiveness and comparative analysis of major AsiaPacific airports. Transport Pol 2013;30:318-26.

[66] Zacharia Z, Mentzer J. Logistics salience in a changing environment. J Bus Logist 2004;25:187-209. 